\title{
第四次纽约大都市地区规划及其启示
}

\section{Fourth Regional Plan of the New York Metropolitan and Its Revelation}

摘要: 纽约大都市地区是美国最重要的社会经济区域之 一。1920 年代以来, 纽约区域规划协会发表了三次区域 规划, 在区域发展方面发挥了重要作用。2013 年面对区 域转型, 纽约区域规划协会启动第四次纽约大都市地区 规划, 提出了“经济机会、宜居性、可持续性、治理和 财政” 四方面议题。文章在现有材料基础上介绍第四次 规划组织情况及主要内容; 并从区域视野、问题演变、 思想转变和规划目标对四次区域规划进行比较; 最后总 结了纽约大都市地区发展及规划的基本经验与启示。

Abstract: The New York Metropolitan Region is one of the most important social economic regions in the United States. Since the 1920s, New York Regional Plan Association(RPA) published three regional plans, which have played an important role in regional development. RPA launched the Forth Regional Plan in 2013, which will focus on the key issues of "economic opportunity, livability, sustainability, governance and fiscal health". This paper introduces the organization and its main contents according to the relevant materials, and compares the four plans from the regional perspective, evolution, ideological change and planning objectives. Finally, it summarizes the New York Metropolitan Region's development, generalizes its basic experience and revelation of regional plans.

关键词：纽约大都市地区; 第四次区域规划; 区域规划协会

Keywords: New York Metropolitan Region;

Fourth Regional Plan; Regional Plan Association

首都区域空间规划研究北京重点实验室、北京市教委重 点学科群建设项目 “城市规划建设与管理”资助

作者: 武廷海, 博士, 清华大学建筑学院教授、博士生导师, 清华大学建筑与城市研究所副所长 高元, 清华大学建筑学院博士研究生
纽约大都市地区（New York Metropolitan Region）包括美国纽约州、 康涅狄格州与新泽西州的一部分, 共 31 个县, 783 个城镇, 面积约 13000 平方英里 (约合 $33669.8 \mathrm{~km}^{2}$ ), 2015 年底居住人口达 2300 万 (图 1)。 纽约区域规划协会（RPA: Regional Plan Association）是非官方、非营利组 织, 由独立的董事会和三个州的市民、社区领导、商人和其他专家组成。 该组织从 1920 年代开始致力提升区域的经济活力、宜居性和可持续发展 能力, 并分别于 1929 年、1968 年和 1996 年发表了对纽约大都市地区的 规划研究成果。2000 年作者曾对这三次区域规划进行简要介绍和比较 ${ }^{[1]}$ 。 2013 年 4 月 19 日, RPA 宣布启动纽约大都市地区第四次规划（Fourth Regional Plan), 为接下来的 25 年地区增长和管理提供策略 ${ }^{[2]}$ 。目前第四 次区域规划编制工作仍在进展当中, RPA 已经发表了一些关于区域问题、

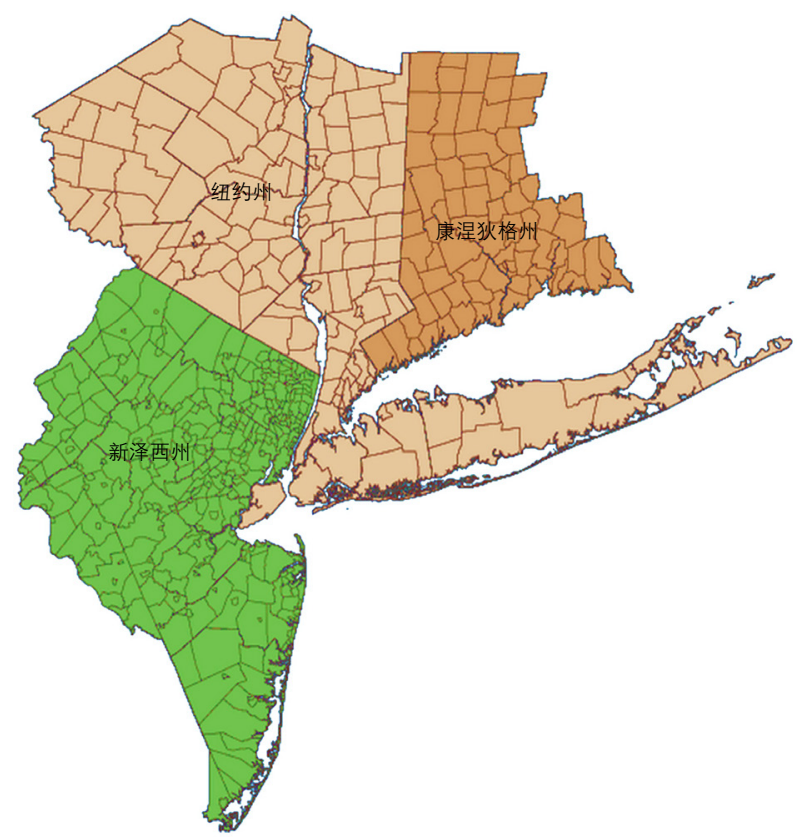

图 1 纽约大都市地区范围

资料来源 : http://fragile-success.rpa.org/c/6.html 
规划目标、应对措施的研究报告, 本文即在此基础上介绍纽 约大都市地区的第四次区域规划, 并提出初步的认识。

\section{1 前三次区域规划回顾}

1914 年巴拿马运河开通, 增加了对纽约港的需求, 纽 约进人大发展时代。从全国范围看, 1920 年美国城市人口超 过农村人口, 大城市人口逐渐向郊区迁移。在高度自治的地 方政府管辖下, 纽约难以有效应对爆炸式增长, 满足区域公 共利益需求，一些区域性的规划工作应运而生。首先，1921 年美国专门成立了跨州合作机构纽约港务局（Port of New York Authority)，着手改善、兴建交通和海港设施，协调港 区发展, 加强大纽约地区的经济竞争能力。纽约港务局是得 到州立法授权的跨州准政府机构，财政上自给自足，出台了 有关港区发展的总体规划, 为纽约大都市地区发展和公共管 理提供了新模式 ${ }^{[3]}$ 。罗斯福在组建田纳西河谷管理局采用了 纽约港务局经验。其次, 1921 年由支持纽约和周边地区改 善工作的罗素·赛奇基金会（Russell Sage Foundation）资助, 查尔斯·诺顿（Charles D. Norton）召集建筑师和规划师，建 立了下属的纽约区域规划委员会 (Committee on the Regional Plan of New York)。该委员会是区域规划探索的纯粹的非政 府机构, 历经 8 年, 于 1929 年发表了《纽约及其周边地区 的区域规划》(Regional Plan of New York and Its Environs)。 当时政府未正式采纳规划, 劳森·帕蒂建议成立私人公司, 在赛奇基金会的支持下, 1929 年正式成立纽约区域规划协 会 (RPA)。《纽约及其周边地区的区域规划》的核心是 “再 中心化” (recentralization), 制定了建立开放空间、缓解交通 拥堵、集中与疏散、放弃高层建筑、预留机场用地、细化设计、 减少财产税、建设卫星城等 10 项政策（图 2) ${ }^{[4]}$ 。这是 RPA 对纽约大都市地区的第一次区域规划，为区域内的物质建设 活动提供了空间框架，在罗斯福新政时期和二战后期为该区 赢得了超过常规份额的联邦政府资金。但是, 规划忽视了中、 低收人人群的住房需求; 且由于铁路私有, 跨区域的轨道交 通规划设想也未能实现。

第二次世界大战结束后, 美国经济再度繁荣。政府鼓励 发展小汽车行业及在城市外围建设, 1962 年的《高速公路 法案》加速了空前的郊区化, RPA 称之为 “蔓延的城市” (spread city), 纽约大都市地区未能实现规划提出的 “再中 心化”。1968 年, RPA 完成大纽约地区第二次区域规划, 规 划的核心是通过“再集中” (reconcentration)，也就是将就业 集中于卫星城, 恢复区域公共交通体系, 以解决郊区蔓延和 城区衰落问题 ${ }^{[5]}$ 。为此, 规划提出了建立新的城市中心、塑 造多样化住宅、改善老城区服务设施、保护城市未开发地区 生态景观和实施公共交通运输规划 5 项原则。此次规划通过
部门协调, 带动纽约大都市地区 10 亿美元的再投资, 保住 了成百上千亩开敞空间, 并对区域通勤铁路系统的建设提供 了正确指导, 但可惜的是规划未能准确预测人口增长趋势和 相应土地供给 ${ }^{[1,6]}$ 。

1990 年代, 纽约大都市地区经济增长缓慢而波动, 区域 发展面临巨大挑战, 既包含技术和全球化竞争, 也包括社会、 环境等问题恶化, 区域财富增长的可持续性和世界领导地位 受到威胁。随着增长管理运动波及全国, 精明增长成为引导 大都市区的基本策略, RPA 重新审视 “财富” 的内涵, 提出 应注重经济、社会、人文和自然的综合发展, 兼顾不同群体 间的利益平衡。1996 年 RPA 发布第三次区域规划—《危 机挑战区域发展》(A Region at Risk), 规划的核心是凭借投 资与政策来重建 $3 \mathrm{E}$, 即经济、公平和环境。通过整合经济、 公平和环境推动区域发展, 从而增加区域的全球竞争力。规 划提出植被、中心、机动性、劳动力和管理 5 大战役来整合 $3 \mathrm{E}$, 提高居民生活质量 ${ }^{\left[{ }^{7]}\right.}$ 。第三次区域规划通过经济可行性 分析确保规划实施，对投资、政策和治理进行了详细安排。 近 20 年来, 纽约地区的城市蔓延、犯罪率得到一定控制, 通 过基础设施投资、棕地开发和公园建设，提升了生活质量。

\section{2 第四次区域规划概况}

总体看来, 纽约大都市地区的前三次规划取得了一定的 成效, 但是气候变化、基础设施落后与恶化、公共机构负债

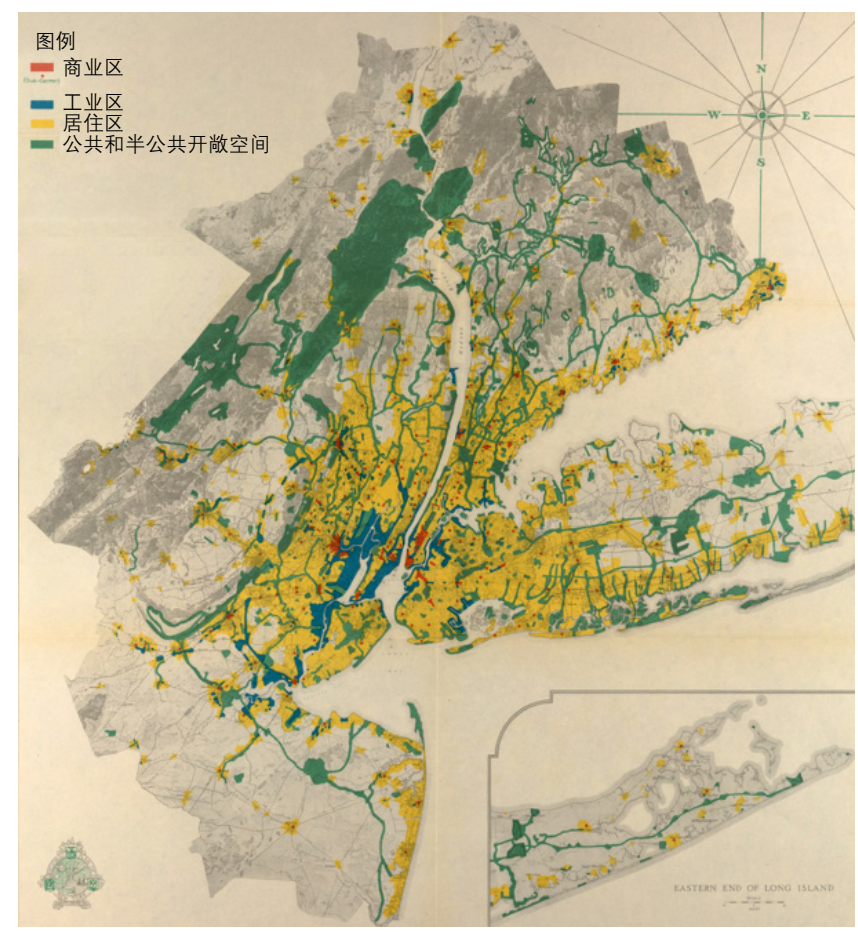

图 2 纽约大都市地区土地利用总体规划（1928 年） 资料来源 : 参考文献 [4] 
制约管理等问题仍然威胁着市民生活, 环境、旅游模式和商 业活动需要跨越行政边界进行区域合作, 失业、住房成本、 物业税和自然灾害等问题受到居民的普遍关注。2014年 RPA 对纽约大都市地区发展发表了题为《脆弱的成功》的评 估报告, 指出当前所面临的问题与威胁, 包括州政府决策割 裂、地方与区域经济结构脱节、四分之三的工薪阶层工资停 滞不前、住房供给缺乏、科技发展和区域气候变化等等, 必 须开展新的区域规划加以应对 ${ }^{[8]}$ 。

\section{1 大纽约地区面临挑战}

在过去 20 年里, 三州地区增加了 230 万居民和 150 万 就业岗位; 由于公共卫生措施和环境改善, 预期寿命增长速 度超过美国平均水平; 犯罪率急剧下降；世界一流的公共交 通系统提供了数百万个工作岗位的工作便利; 交通客流量增 加。目前, 纽约成为美国最安全的城市, 越来越多的居民愿 意在这里生活。但同时, 大纽约地区也面临一系列挑战。

(1) 大多数人的机会有限。1990 年以来一半社会底层 居民的收人降低了 $14 \%$, 四分之三的居民平均收人下滑。很 多企业的最大收益是给员工最低工资, 经济变化导致高薪工 作的就业率下降, 这一代人面临工资停滞和负担能力的危机, 仅从事专业服务和商业的人群有较好的前景 (图 3)。三州地 区的种族隔离和阶级限制依然严峻, 很多贫困和非白人社区 儿童无法享受高质量的公共教育, 高质量学校分布与收人水 平和社区中白人所占比例呈正比。家庭收人在 10 万美金以 上的社区中, 高质量学校占近一半; 家庭收人在 4 万美金以 下的社区中, 高质量学校拥有量不到 $5 \%$, 低质量学校拥有 量却超过 $50 \%$ 。黑人社区中有超过 $50 \%$ 的学校质量差, 白 人社区中近 $40 \%$ 的学校质量好（图 4)。

（2）生活成本上升制约了生活质量和经济繁荣。由于政 府过度依赖于房产税, 房产税占家庭收人较大份额, 外加交 通成本, 两者占据一半家庭收人, 剩下的收人难以支付医疗、

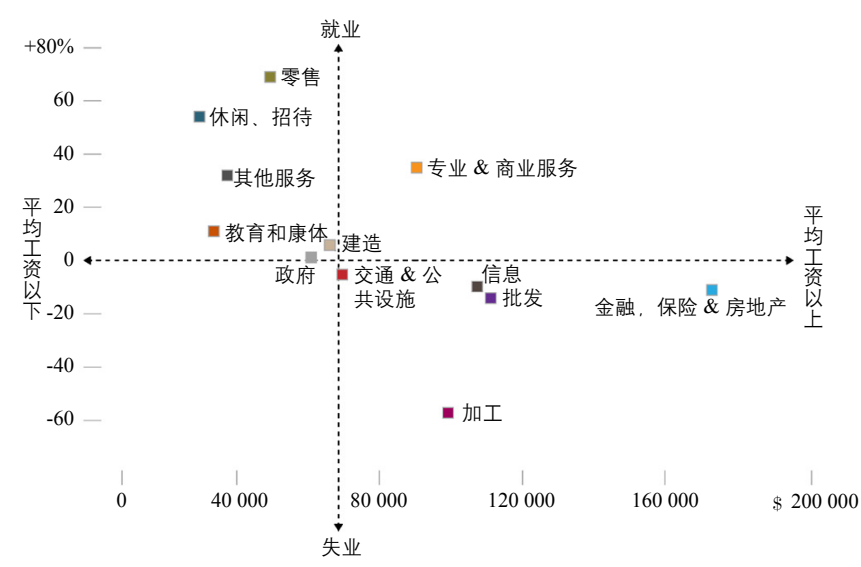

图 3 1990一2013 年纽约大都市地区就业部门变化 资料来源 : http://fragile-success.rpa.org/c/2.html
教育、抚养等开销, 可自由支配的收人较少, 可支付能力已 经成为居民的最大担忧（图 5)。大纽约地区是典型的高附 加值、高教育水平和生意高成本的大都市, 当收人不能与生 活成本增长相匹配, 就难以吸引和留住有才华的员工, 房地 产市场鼎盛的 2006 年是居民迁移的巅峰（图 6)。

（3）郊区落后。纽约大都市地区郊区就业增长比城市弱 得多, 并且贫困率上升速度加快。城市型、步行社区需求不 断增长, 市区多样化的社区建设速度远超过了郊区, 进人城 市生活的年轻人增多, 据调查统计, 18 29 岁的年轻人有一 半喜欢在城市生活（图 7)。郊区的衰落制约整个区域的繁荣, 作为一个区域整体, 纽约和其他城市依赖郊区的劳动力, 城 市和郊区需要多元化社区。郊区房价应该满足不同人的收人 水平, 否则在解决住房问题上城市将负担更重。

（4）三州地区越来越容易受到灾难威胁。气候变化威胁 区域发展, 沿海地区一些重要的基础设施分布在洪水区范围 内, 公共住宅达 $21 \%$ 、发电站达 59\%、地铁和铁路站达 $13 \%$ (图 8)。复杂的科学技术增加了系统故障的风险, 老化的 基础设施和数十年的投资不足加剧了灾难性事件的风险。

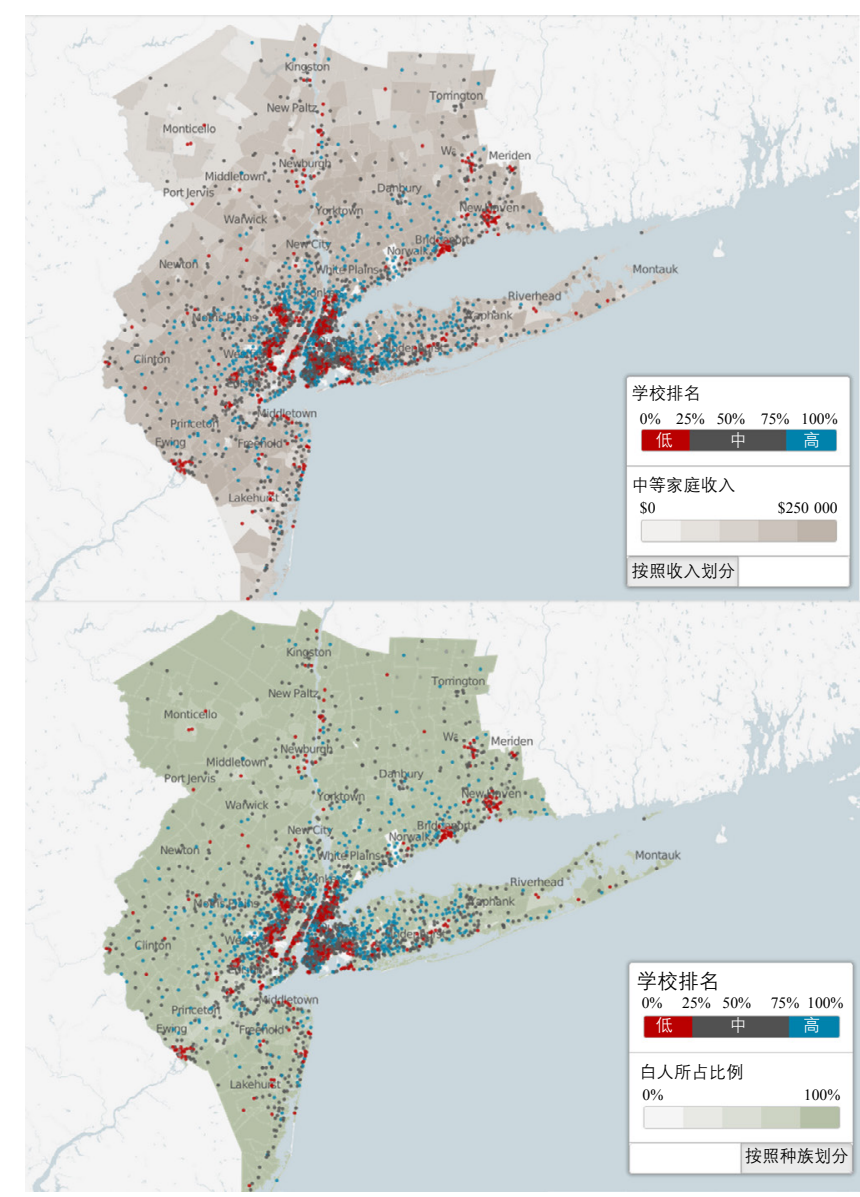

图 4 家庭收入 (上) 和种族 (下) 与高质量学校相关性 资料来源 : http://fragile-success.rpa.org/c/2.html 


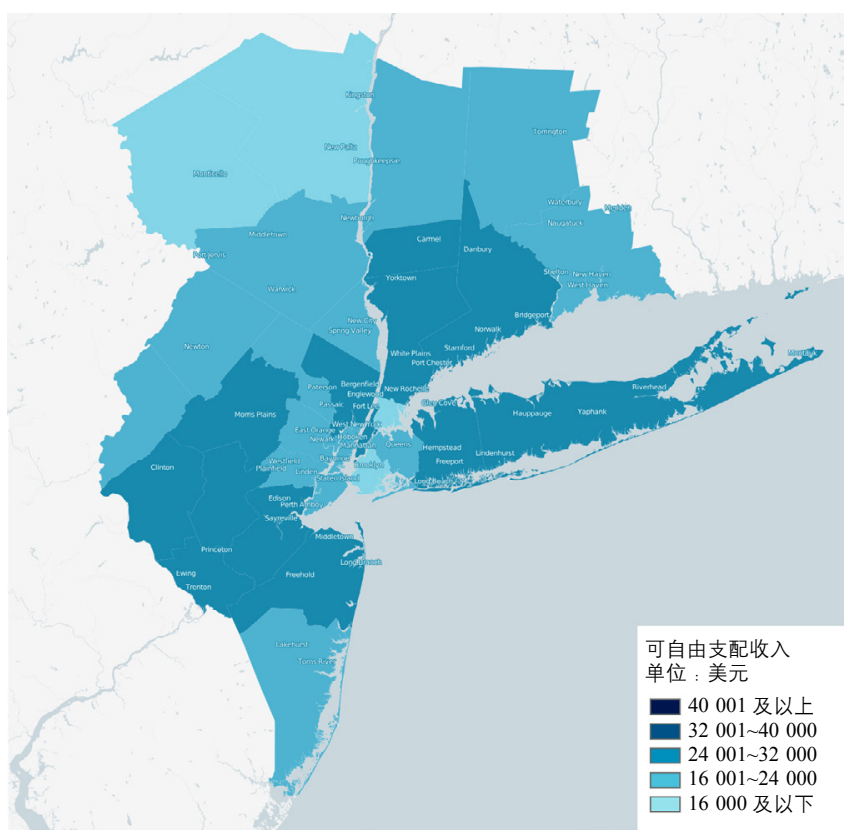

图 5 居民可自由支配收入

资料来源 : http://fragile-success.rpa.org/c/3.html

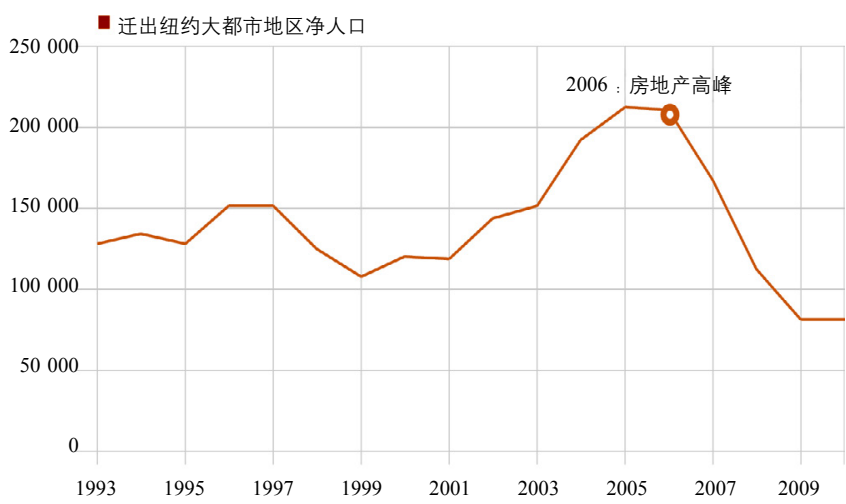

图 6 1993-2009 年纽约大都市地区人口迁出 资料来源 : http://fragile-success.rpa.org/c/3.html
（5）政府决策不能满足区域发展需求。政府机构负担能 力弱, 在建设和开发社区中法律法规不完善、未降低成本, 导致共享公共服务效率低。没有修改税收结构促进经济更有 效率和多元化, 没有建造新的公共交通工具帮助人们在更短 的时间内得到更多的就业和学习机会, 没有投资技术和基础 设施系统, 导致社会和经济面临灾难时弹性弱。为长期计划 设置的机构未能独立行事, 大部分大型基础设施项目未能按 时、按预算交付, 融资结构不清楚。除此之外, 政府官员腐 败, 导致公众对政府的信任度下降。公众税收没有得到公平 的回报，政府的决策没能尊重纳税人的需求。

\section{2 规划议题与规划组织}

第四次纽约大都市地区规划围绕目前最紧迫的气候变 化、财政不确定性和经济机会下降等挑战展开, 提出了 “经 济、包容性和宜居性” 目标 ${ }^{[9]}$ 。预计到 2040 年, 增加 190

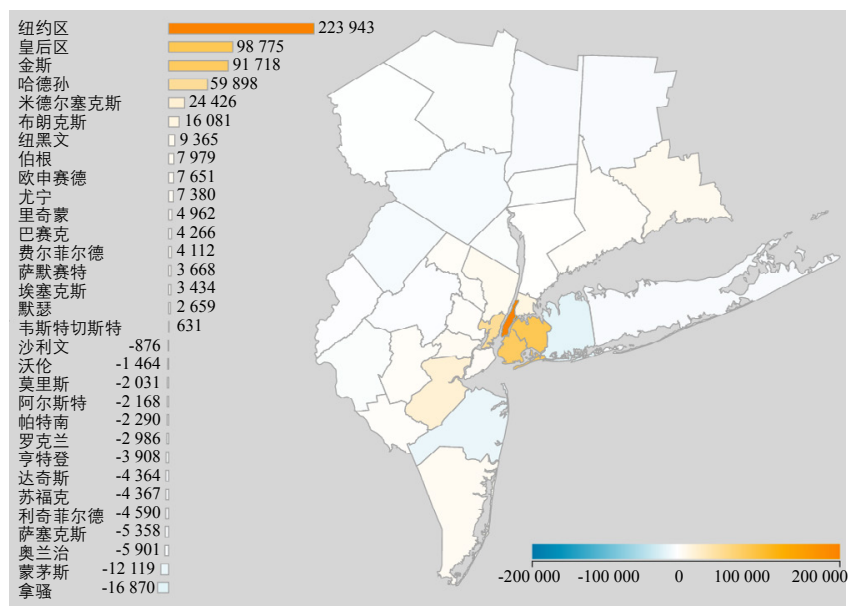

图 $72000-2010$ 年 20 34 岁人口迁入净数量 资料来源 : http://fragile-success.rpa.org/c/4.html

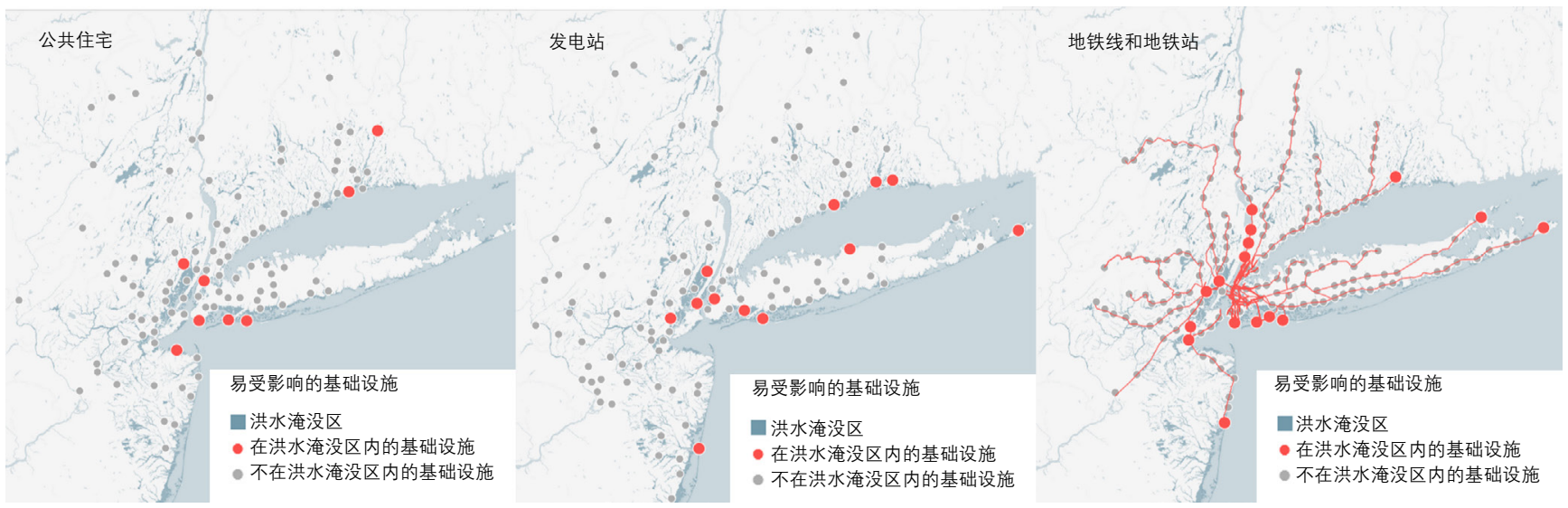


万就业岗位和 370 万人口 ${ }^{[10]}$ 。规划编制由纽约区域规划协会 主导, 专家、公民、企业和社区领袖共同参与, 分为八个工 作小组: 气候、社区、经济发展、能源、融资和治理、住房、 公园和风景、交通运输, 倡导通过多种渠道促进规划过程中 的公众参与 ${ }^{[1]}$ 。

第四次区域规划重点是 “区域转型” ${ }^{[12]}$, 确定了 “经济 机会、宜居性、可持续性、治理和财政” 四方面议题, 旨在 创造就业, 改善商业环境, 促进经济增长, 减少家庭的住房 开支, 解决贫穷, 为居民提供更加富裕的生活和更多、更便 利的社会服务设施 (交通、教育); 为居民营建更加安全、 健康和活力的社区; 从区域视野解决气候、基础设施等问题; 在区域层面进行改革, 提供更好的决策和更有效的治理 ${ }^{[1]}$ 。

\section{3 前期研究报告与结论}

RPA 围绕第四次区域规划发表了《空间规划与不平 等》 ${ }^{[13]}$ 、《工作的未来》 ${ }^{[14]}$ 、《城市中心区的未来》 ${ }^{[15]}$ 、《强 化哪里, 弱化哪里? 》 ${ }^{[16]}$ 四份白皮书 (表 1)。通过基础设施 投资扩容、建设多样化中心区、改善城市环境, 提升居住环 境质量。提供多样化的住宅和购物形式, 解决低收人人群和 少数人群就业及子女教育问题, 实现社会公平。为适应经济 结构的变化, 着眼全球、区域范围, 通过商业系统、信息设施, 加强区域范围内生产力要素流通。通过多种方式建设弹性的 生态系统, 控制和减少二氧化碳排放, 增加城市抵抗灾害能力。

\section{4 弹性规划}

针对区域发展的威胁与不确定性, RPA 提出了 “弹性” (resilience) 的概念, 指在提升从最近的冲击和压力中快 速恢复, 并且减少未来产生风险漏洞的能力 ${ }^{[16]}$ 。RPA 分析 2050 年纽约大都市地区洪水风险和社会脆弱性（图 9), 提 出弹性规划需要基于不同的时间框架、制度、政治能力、财政、 社会和环境成本等因素, 综合成本和效益、限制和协同效应, 组合 $5 \mathrm{R}$ 策略解决问题, 并形成社会共识。增加区域弹性的
$5 R$ 途径 :

- 重建 (Rebuilding) 一一更好、更安全的标准 ;

- 抵制 (Resisting) 一一通过工程措施抵抗洪水;

- 保留 (Retaining) 一一通过绿色基础设施保留风道和 雨水;

- 恢复 (Restoring) ——恢复和增强保护性与生产性自 然系统;

- 撤退 (Retreating) 一一洪水平原和高风险的风浪地 区撤退, 工程技术无法解决或者成本过高, 高风险的地区撤 退是可行的, 居民可以异地安置。

\section{3 四次区域规划比较}

近百年来, 针对纽约大都市地区所处的经济形势和全球

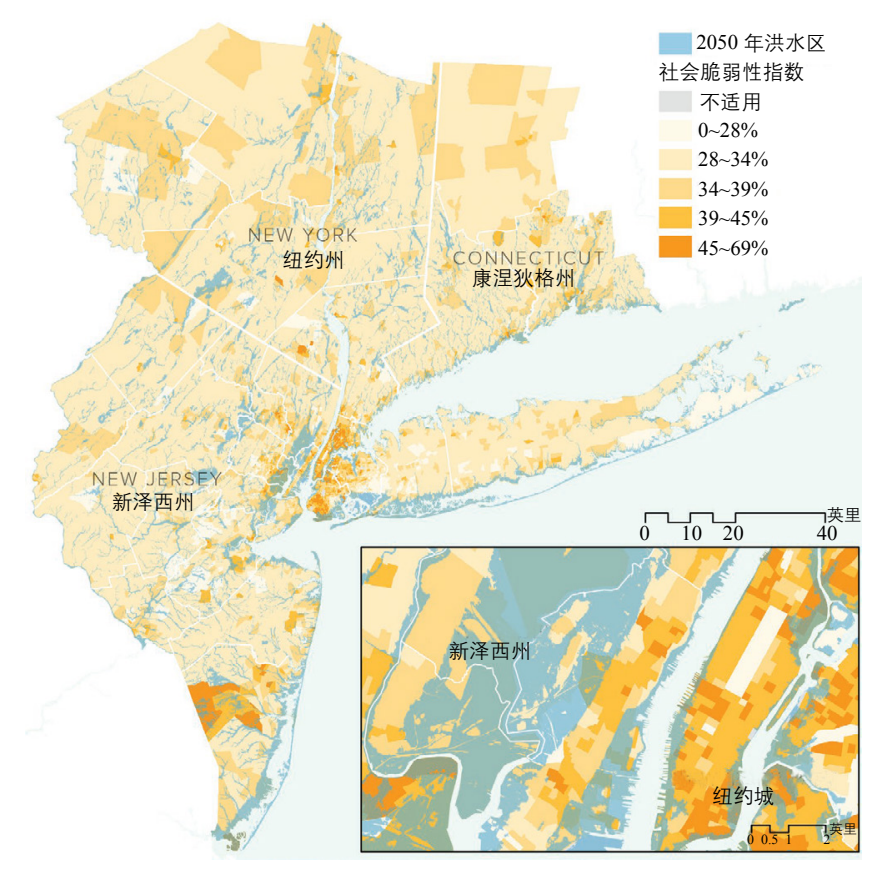

图 9 社会脆弱性和 2050 年洪水风险 资料来源 : 参考文献 [16]

\section{表 1 第四次规划发表的白皮书的主要内容}

\begin{tabular}{|c|c|c|}
\hline & 目标 & 措施 \\
\hline 空间规划与不平等 & $\begin{array}{l}\text { 跨越种族、民族、收人和地理界 } \\
\text { 限, 增加经济机会, 提高生活质量, } \\
\text { 实现 “社会公平” }\end{array}$ & $\begin{array}{l}\text { 扩大基础设施容量 ; 增加各种族、各收入阶层进入高品质生活的机会; 提供支付得起的居住和商业 } \\
\text { 选择性 ; 创造多样的居住和工作形式 ; 建立更多可恢复的建设环境和自然系统 ; 提高区域体系和管 } \\
\text { 理体系的效率 }\end{array}$ \\
\hline 工作的未来 & $\begin{array}{l}\text { 区域老龄化; 教育水平改善, 适 } \\
\text { 应经济和劳动力结构改变 }\end{array}$ & $\begin{array}{l}\text { 加强全球和区域范围内的连通性 ; 区域范围内商业综合系统规划; 信息基础设施规划 ; 优先考虑空 } \\
\text { 间和系统规划中的灵活性和弹性; 低收人和少数民族子女上学便捷性; 创造中心区和街区居住、工作、 } \\
\text { 游㮩更多的选择性和便捷 }\end{array}$ \\
\hline 城市中心区的未来 & $\begin{array}{l}\text { 控制菖延, 解决城市病; 营建活力、 } \\
\text { 宜居的中心区 }\end{array}$ & $\begin{array}{l}\text { 如何定义一个成功的中心区? 为什么一些中心区成功, 而其他的衰败? 如何强化那些可能不生长的 } \\
\text { 中心区? }\end{array}$ \\
\hline 强化哪里, 弱化哪里? & 建设安全、舒适、健康的城市 & 重建；抵制；保留；恢复；撤退 \\
\hline
\end{tabular}

资料来源 : 作者根据参考文献 [13-16] 总结整理 
趋势, RPA 的规划研究提出了相应的策略。兹从背景、问题、 目标、核心、措施、范围、影响七个方面, 对四次区域规划 加以比较, 列表如下 (表 2)。

为进一步加深对纽约大都市地区四次区域规划的认识, 下文从区域视野、问题演变、思想转变、规划目标四方面作 进一步阐述。

\section{1 区域视野}

第一次大纽约地区的规划范围包括 22 个县, 5528 平方 英里（合 $14317 \mathrm{~km}^{2}$ ), 尽管芒福德认为这个规划仅涉及纽 约市及其周边地区, 还算不上真正意义上的区域规划 ${ }^{[17]}$, 但 不可否认的是这次规划具有突出的区域视野, 努力将城市和 周边区域作为整体考虑 ; 第二次区域规划的空间范围扩大至 12750 平方英里 (合 $33022 \mathrm{~km}^{2}$ ), 是第一次的 2.3 倍（图 10）; 第三次区域规划的空间范围扩大至 31 个县, 13000 多平方 英里。目前, 纽约大都市地区已经成为美国东北部巨型区域 世界级城市群的重要组成部分。第四次区域规划为应对全球 气候变化等威胁, 组建了国际咨询委员会, 试图通过全球思 考与实践来整合纽约, 通过动员各种跨国联盟资源以确保计 划的实现, 提升区域的可持续发展能力。

\section{2 问题演变}

从根本上讲, RPA 的四次纽约大都市地区规划是不同时 期对社会经济需求的回应。第一次区域规划面临的主要问题 是如何适应城市爆炸式增长, 物质空间建设落后于经济增长
速度 ; 第二次区域规划面临的是郊区蔓延和中心区衰败、土 地等资源浪费、种族隔离等社会问题 ; 第三次区域规划主要 针对综合的经济、社会、环境问题, 如郊区化加剧、公共交 通低效、社会分化等; 第四次区域规划除了要应对经济发展 问题, 还面临 “人”的需求难以满足和自然灾害频发问题。

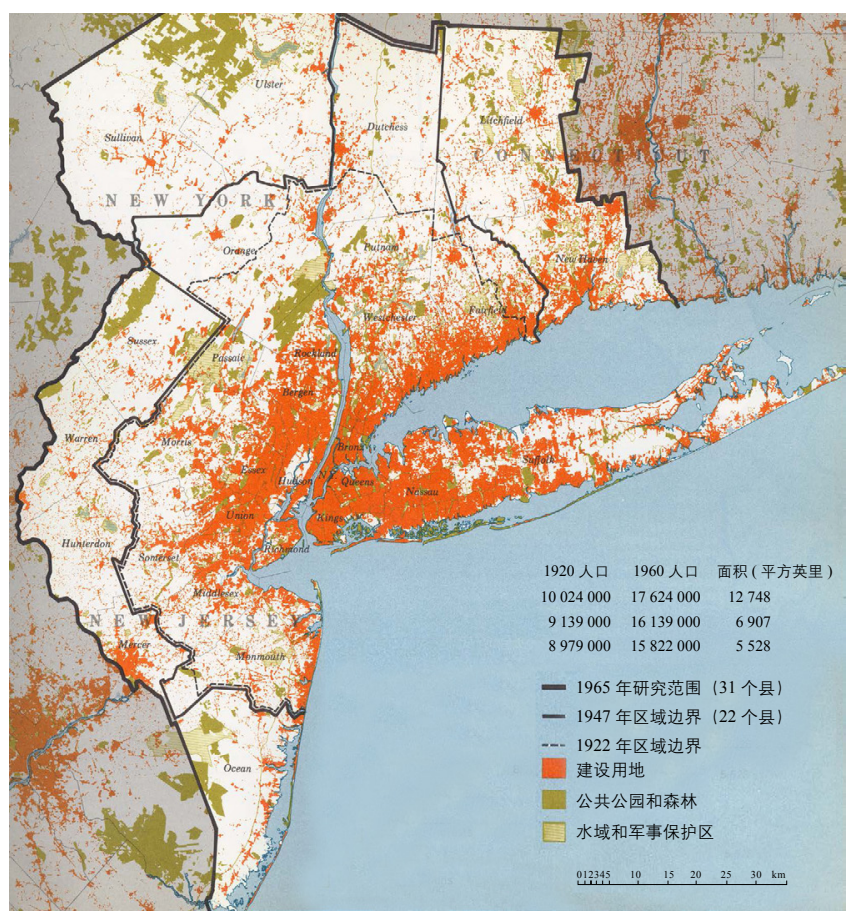

图 10 大纽约地区规划研究范围的比较 (1922、1947、1965 年) 资料来源 : 参考文献 [5]

\section{表 2 纽约大都市地区四次区域规划比较}

\begin{tabular}{|c|c|c|c|c|}
\hline & 第一次区域规划（1929 年） & 第二次区域规划（1968 年） & 第三次区域规划（1996 年） & 第四次区域规划（2016 年） \\
\hline 背景 & 第一次世界大战后, 城市爆炸式增长 & 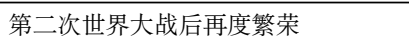 & 可持续发展、精明增长理念引领发展 & 区域抵抗自然灾害的可恢复能力差 \\
\hline 问题 & 地方性政府限制经济增长 & $\begin{array}{l}\text { 公共交通规划未实施; 土地消费量剧 } \\
\text { 增 ; 交通通勤 ; 社会隔离 ; 公共设施 } \\
\text { 缺乏; 城乡缺乏自然联系 }\end{array}$ & $\begin{array}{l}\text { 世界地位动摇 ; 大规模失业、区域投 } \\
\text { 资减少 ; 社会问题、环境问题 ; 郊区 } \\
\text { 化加剧 ; 公共交通 }\end{array}$ & $\begin{array}{l}\text { 生活成本增加; 基础设施衰败; 环境 } \\
\text { 危险; 管理缺乏; 大多数人机会有限 }\end{array}$ \\
\hline 目标 & $\begin{array}{l}\text { 重构区域秩序, 提供区域范围内更多 } \\
\text { 的机会 ; 世界最大、最具活力和丰富 } \\
\text { 多样的大都市地区之一 }\end{array}$ & $\begin{array}{l}\text { 控制蔓延, 加强对基础设施和中心区 } \\
\text { 的投资; 复兴市区, 解决环境退化、 } \\
\text { 旧中心区衰退等问题 }\end{array}$ & $\begin{array}{l}\text { 经济、公平和环境提高城市居民生活 } \\
\text { 质量, 实现城市与区域的可持续发展 }\end{array}$ & $\begin{array}{l}\text { 培育更多具有经济性的和可持续的社 } \\
\text { 区; 经济性、包容性和宜居性的发展, } \\
\text { 应对气候等灾害 }\end{array}$ \\
\hline 核心 & 再中心化 & 再集中 & 重建 3E & 区域转型 \\
\hline 措施 & $\begin{array}{l}\text { 制定区划; 建立开放空间 ; 缓解交通 } \\
\text { 拥堵 ; 集中与疏散 ; 放弃高层建筑 ; } \\
\text { 建设公共空间 ; 预留机场用地 ; 细化 } \\
\text { 设计 ; 减少财产税 ; 建设卫星城 }\end{array}$ & $\begin{array}{l}\text { 建立新的城市中心; 塑造多样化住宅; } \\
\text { 改善老城区服务设施; 保护城市未开 } \\
\text { 发地区生态景观 ; 实施公共交通运输 } \\
\text { 规划 }\end{array}$ & 植被; 中心 ; 机动性 ; 劳动力 ; 管理 & $\begin{array}{l}\text { 增加收人, 减少贫困; 扩大住房选择; } \\
\text { 复兴城市中心区; 增加公共需求税收; } \\
\text { 社会福利 ; 公共基础设施建设 ; 重建、 } \\
\text { 抵制、保留、恢复、撤退 }\end{array}$ \\
\hline 范围 & 22 个县, 5528 平方英里 & 23 个县, 12750 平方英里 & $\begin{array}{l}31 \text { 个县、 } 800 \text { 个城镇 } 2000 \text { 万居民, } \\
\text { 面积 } 13000 \text { 平方英里 }\end{array}$ & $\begin{array}{l}31 \text { 个县、 } 783 \text { 个城镇 } 2300 \text { 万居民, } \\
\text { 面积 } 13000 \text { 平方英里 }\end{array}$ \\
\hline 影响 & $\begin{array}{l}\text { 奠定区域发展物质框架基础; 成立重 } \\
\text { 要的新机构; 世界上首次大都市地区 } \\
\text { 综合性、长期性规划, 影响国外区域 } \\
\text { 规划工作 }\end{array}$ & $\begin{array}{l}\text { 奠定 } 1980 \text { 年代纽约区域的再发展; } \\
\text { 拓展公众参与概念 ; 为了共同利益, } \\
\text { 促进不同部门、机构之间的合作 }\end{array}$ & $\begin{array}{l}\text { 重视规划可行性 ; 呼吁政府与企业之 } \\
\text { 间、地方与地区之间进行利益协调 ; } \\
\text { 重新审视了 “财富” 的含义 }\end{array}$ & $\begin{array}{l}\text { 强调人的重要性; 规划参与的多元 } \\
\text { 化; 推进规划编制和政府治理改革; } \\
\text { 首次应对气候等灾害, 从区域层面提 } \\
\text { 出策略 }\end{array}$ \\
\hline
\end{tabular}


总体看来, 规划关注的重点逐步从城市物质空间, 转向经济、 社会、环境目标, 追求人的全面发展和自然灾害应对, 这些 方面直接影响着区域发展目标制定。

\section{3 思想转变}

1920 年代以来, “大都市主义” (metropolitanism) 和 “区 域主义”（regionalism）两个区域规划传统共同影响着纽约大 都市地区发展, 其中“大都市主义” 试图从区域范围来满足 大都市发展的需要, “区域主义”试图从区域范围内进行均 衡的布局 ${ }^{[18]}$ 。第一次区域规划提出 “再中心化”, 究其本质 是 “大都市主义”, 希望通过调查整个大纽约都市地区, 用 大规模的组织和财政预算实现区域范围内的调整, 强化纽约 的中心地位, 芒福德曾与亚当斯争论即认为第一次区域规划 没有从区域整体发展出发, 是 “将城市功能化运用于区域规 模”; 第二次区域规划提出 “再集中”, 建设多中心体系, 实 际上关注的是 “经济景观” ; 第三次区域规划思想融合了 “新 城市主义”、“精明增长” 等规划思潮, 核心是通过整合 $3 \mathrm{E}$, 提高生活质量, 更加强调区域范围内的协调发展和综合性目 标发展; 第四次区域规划提出了增加城市弹性的 $5 \mathrm{R}$ 原则。 总体看来, 大纽约地区四次区域规划思想的转变, 折射出美 国区域规划思想从大都市主义、区域主义到区域科学、再到 新区域主义（强调多维发展目标）的转变 ${ }^{[19]}$ 。

\section{4 规划目标}

针对不同时期所面临的矛盾与问题, 规划提出了相应的 目标。第一次区域规划致力于将纽约大都市地区打造成 “世 界最大、最具活力和丰富多样的大都市地区之一”, 通过物 质空间建设重构区域秩序、解决城市问题, 安排大都市地 区物质发展的基本要素 ${ }^{[1]}$, 提供区域范围内更多的机会。第 二次区域规划规划目标转向 “控制蔓延, 复兴市区, 加强 基础设施投资, 改善环境退化”, 提倡政府之间的横向与纵 向合作。第三次区域规划旨在通过整合经济、社会和环境, 实现 “城市居民生活质量, 实现城市与区域的可持续发展”。 第四次区域规划提出 “经济性、包容性和宜居性的发展” 的规划目标, 强调增强抵抗自然灾害的能力, 培育更多具 有经济性的和可持续的社区, 注重解决低收人人群和少数 族群的就业、生存和社会隔离。总体看来, 规划目标从“以 物质空间为主” 转变为 “以人为本”, 并且注重突出重点与 有限目标。

\section{4 百年纽约发展及其规划的基本经验与启示}

近百年来, 纽约经历了多次大规模的经济危机和社会动 荡, 如 1930 年代的大萧条、1960 年代的城市骚乱、1970 年
代的财政危机、21 世纪初的“9·11”恐怖袭击、2008 年的 金融危机, 等等, 都对纽约及其周边地区的发展产生了不同 程度的影响。在此过程中, RPA 开展四次区域规划, 针对社 会经济问题与挑战, 通过不断完善区域规划方法, 探寻大都 市持续发展的区域途径，推进公共基础设施投资建设、自然 生态环境保护、居民生活质量提升, 积累了一定的经验, 同 时也为世界大都市地区的规划发展提供了有益启示。

\section{1 寻求解决大城市发展的区域途径}

芒福德曾经说过, “区域规划是一种进步的适应社会变 化的方法” ${ }^{[17]}$, 区域是解决大城市发展问题较为合适的空间 平台。RPA 第一次区域规划认为, 区域可以 “减少与市场冲 突、解决交通拥堵和经济困难”。事实上, 就像戈特曼在美 国东北海岸大都市带研究中指出的, “1920-1950 年代中心 城市规模继续扩大, 其集聚能力达到顶点, 是大都市带的雉 形阶段。1950年代后由于郊区化大都市地区的空间范围拓展, 是大都市带成熟阶段” ${ }^{[20]}$ 。后来 RPA 的大纽约地区规划也 表明, 区域是研究解决问题所需要的尺度与背景, 在这个范 围内提出解决当前发展矛盾的策略, 区域规划是适应社会风 险、自然风险、经济危机的重要手段和工具。通过区域途径, 政府的事务走向跨政府, 寻求跨区域合作, 创新合作体制和 机制，合理地统筹资源配置，促进区域整体发展。

\section{2 基础设施投资引导与管理协调区域整体发展}

基础设施的建设为区域范围内生产要素的流动提供了 载体, 通过规划引导基础设施的合理布局有利于协调区域 发展。早在港务局成立之前, 纽约就分别于 1857 年和 1866 年成立了负责治安和健康的大都市委员会, 这些区域规划和 治理组织是由基础设施投资企业在政府架构外培育的, 是 实现区域协调发展的先驱。RPA 的纽约大都市地区规划注 重通过基础设施的投资建设促进区域整体发展, 例如高速 公路建设将区域形成一个整体, 带动经济快速增长。第一 次和第二次区域规划中关于铁路的规划由于铁路私有化而 未得到实施, 影响了周边到达中心区的可达性和居民的工 作便利。在经济萧条时期, 区域学校、铁路系统、自然保护、 社区等基础设施投资减少, 带来了严重的环境问题和就业 问题，制约了区域整体的竞争力。第四次区域规划通过现 代化基础设施投资, 扩大产能, 以提高城市的经济竞争力 和发展韧性。

\section{3 着眼于综合的城市发展竞争力的提升}

着眼于纽约大都市地区城市发展竞争力的提升, 规划的 目标也从单纯的追求经济增长转变为多维度的发展。第三次 
和第四次区域规划反思和重审了“财富”与 “成功” 的真正 内涵, 即经济、社会和环境发展并存, 注重环境, 关心弱势 群体, 主张公平, 将与人类居住相关系的经济、政治、生态、 社会、文化, 逐渐纳人到了区域发展框架之中。区域发展需 要解决一定区域范围内两个维度的问题, 即城市土地空间的 水平维度和城市增长的垂直维度。城市土地空间的水平维度 应协调人口、土地、经济的发展关系; 城市增长的垂直维度 应该认清区域以及大城市的发展规律, 在全球化影响下辨明 外界变化和发展的不确定性, 依赖社会改良和政府干预, 提 出相应的政策和计划。

\subsection{RPA 形成了一套较为成熟的规划范式}

“如果区域发展想作得更好, 就必须设立有法定资格的、 有规划和投资权力的区域性权威机构” ${ }^{[21]}$ 。RPA 提出的主要 策略和投资建议之所以能够被政府采纳, 甚至影响世界大城 市规划, 主要是因为规划自身的科学性, 依靠制定规划的权 威性、董事成员的地位、研究成果的可信度以及其倡导项目 的有效性以推动规划实施和执行 ${ }^{[6]}$ 。RPA 组织高校、科研单 位、政府机构以及社区市民，通过多种形式的公众参与宣传、 论证、协商解决措施 ; 与建设联盟组织和市民一起为区域领 导人提出发展建议。

\section{5 多学科合作与持续的科学研究}

区域规划离不开持续的多学科合作研究的支撑。RPA 的 第一次大纽约地区规划花了七年的时间, 融合经济学、法学 和社会学等多学科来研究区域的复杂结构。第四次规划在气 候、社区、经济发展、能源、融资和治理、住房、公园和风 景、交通运输方面, 通过调研、可用性数据分析与趋势判断, 分情景模拟。近百年来开展多学科合作集思广益, 持续开展 纽约大都市地区的规划研究, 这是一个非官方的、非营利性 组织的研究报告能够发挥独特社会影响力的根本保障。在此 过程中, 随着科技水平的提升, 区域规划的方法也不断改进, 特别是通过定性、定量分析判断区域发展趋势，通过公众参 与形式的多样化, 获取社会意见, 形成社会共识, 适应多变 的世界, 有效促进了纽约大都市地区的可持续发展。

目前, 我国正开展城市群与区域规划工作, 特别是京 津冀地区协同发展成为国家战略, 2015 年 3 月国家制定《京 津冀协同发展规划纲要》, 2016 年 2 月发布《“十三五” 时 期京津冀国民经济和社会发展规划》。京津冀协同发展有 利于解决北京城市病, 优化区域发展格局, 增强世界竞争 力, 培育新的增长极。1990 年代以来清华大学持续开展京 津冀地区城乡空间发展规划研究, 并先后发布了三期研究 报告 ${ }^{[22-24]}$, 第四期研究正在酝酿之中。比较大纽约地区与
大北京地区的规划建设将是一个饶有意义的学术话题, 待 另文论之。

\section{参考文献}

[1] 武廷海. 纽约大都市地区规划的历史与现状一一纽约区域规划协会的 探索 [J]. 国外城市规划, 2000(02): 3-7, 43 .

[2] RPA. RPA Launches Fourth Regional Plan[EB/OL]. http://www.rpa.org/ article/rpa-launches-fourth-regional-plan, 2013-04-19.

[3] 洪文迁. 纽约大都市规划百年: 新城市化时期的探索与创新 [M]. 厦门 : 厦门大学出版社, 2010.

[4] Regional Plan Association. The Regional Plan of New York and Its Environs[M]. Philadelphia: WM.F. FELL Co. Printers, 1929.

[5] Regional Plan Association. The Second Regional Planning: A Draft for Discussion[R]. New York, 1968.

[6] Robert D.Yaro. Strategic Planning for Global City Regions[R]. Beijing, 2014.

[7] Robert D.Yaro, Tony Hiss. A Region at Risk: The Third Regional Plan for the New York-New Jersey-Connecticut Metropolitan Area[M]. Washington, DC: Island Press, 1996.

[8] Regional Plan Association. RPA Fragile Success: Taking Stock of the New York Metropolitan Region[EB/OL]. (2014-04). http://fragile-success.rpa. org/ 2014.

[9] Greg Clark. New York's Fourth Regional Plan[EB/OL]. (2014-10-07). http://jllblog.com/cities/2014/10/07/new-yorks-fourth-regional-plan/.

[10] Pierina Ana Sanchez. Fourth Regional Plan: The Region in 2040[R].New York, January 20, 2016.

[11] RPA. The Fourth Regional Plan[EB/OL]. http://www.rpa.org/node/6803.

[12] Juliette Michaelson. How We're Creating the Fourth Plan[EB/OL].[201605-04]. http://www.rpa.org/spotlight/how-were-creating-fourth-plan.

[13] Regional Plan Association. Spatial Planning and Inequality[R]. New York: RPA February 23, 2015.

[14] Regional Plan Association. The Future of Work[R]. New York: RPA February 26, 2015.

[15] Regional Plan Association. Future of Downtowns[R]. New York: RPA February 27, 2015.

[16] Regional Plan Association. Where to Reinforce, Where to Retreat? [R]. New York: RPA March 4, 2015.

[17] Mumford, Lewis. The Culture of Cities[M]. New York: Harcourt, Brace and Co., 1938.

[18] Robert Fishman. The American Planning Tradition: Culture and Policy[M]. Washington, DC: Woodrow Wilson Center Press; Baltimore, Md.: Distributed by The Johns Hopkins University Press, c2000.

[19] Stephen M Wheeler. The New Regionalism: Key Characteristics of an Emerging Movement[J]. Journal of the American Planning Association, 2002(03): 267-278

[20] Gottmann Jean. Megalopolis: The Urbanized Northeastern Seaboard of the United States[M]. New York: The Twentieth Century Fund. 1961.

[21] 刘易斯. 芒福德. 刘易斯. 芒福德著作精萃 [M]. 宋俊岭, 译. 北京：中 国建筑工业出版社, 2010 .

[22] 吴良镛, 等. 京津冀地区城乡空间发展规划研究 [M]. 北京: 清华大学 出版社, 2002.

[23] 吴良锯, 等。京津冀地区城乡空间发展规划研究二期报告 [M]. 北京: 清华大学出版社, 2006.

[24] 吴良锯，等。京津冀地区城乡空间发展规划研究三期报告 [M]. 北京： 清华大学出版社, 2013.

(本文编辑：王枫) 